\title{
Co-benefits of forest carbon projects in Southeast Asia
}

\author{
Tasya Vadya Sarira $\oplus^{1,2,3} \llbracket$, Yiwen Zeng $\oplus^{2,3,4} \llbracket$, Rachel Neugarten $\oplus^{5,6}$, Rebecca Chaplin-Kramer $\left(\oplus^{7,8}\right.$ \\ and Lian Pin Koh $\oplus^{2,3 凶}$
}

\begin{abstract}
Forest carbon projects can deliver multiple benefits to society. Within Southeast Asia, $\mathbf{5 8 \%}$ of forests threatened by loss could be protected as financially viable carbon projects, which would avoid $835 \mathrm{MtCO}_{2} \mathrm{e}$ of emissions per year from deforestation, support dietary needs for an equivalent of 323,739 people annually from pollinator-dependent agriculture, retain $78 \%$ of the volume of nitrogen pollutants in watersheds yearly and safeguard 25 Mha of Key Biodiversity Areas.
\end{abstract}

Forest conservation is an important nature-based solution for achieving the goal of the Paris Climate Agreement to limit global warming to below $2{ }^{\circ} \mathrm{C}$ (refs. ${ }^{1,2}$ ). Growing demand for high-quality, nature-based carbon credits from the private and public sectors to meet their climate and sustainability goals presents new opportunities for carbon projects to deliver climate and other benefits to society ${ }^{2,3}$.

Southeast Asia consists of approximately 196 million ha of tropical forests, many of which are under threat from agricultural expansion and other economic activities ${ }^{4}$. It was estimated that deforestation in the region contributed to $2.56 \mathrm{GtCO}_{2} \mathrm{e} \mathrm{yr}^{-1}$ of emissions between 2005 and $2010^{5}$, and further losses will probably exacerbate climate change impacts. There is thus great potential to implement large-scale carbon projects in the region that focus on avoided deforestation as a nature-based climate solution, with countries such as Cambodia already committing to a $59.1 \%$ reduction of their emissions from forestry in their Nationally Determined Contributions by $2030^{6}$.

Importantly, forests within carbon projects also provide essential contributions to people, including pollination service for pollinator-dependent agriculture and water quality regulation, as well as biodiversity conservation ${ }^{1,4}$. Certification bodies and standards typically account for the climate mitigation potential of forest carbon projects, with the abovementioned co-benefits increasingly recognized through standards such as the Gold Standard (goldstandard.org) and Verra's Climate, Community and Biodiversity Standard (verra.org/project/ccb-program) ${ }^{3,7}$.

Yet, these co-benefits are typically documented at the project level and are typically only measured qualitatively rather than being systematically considered or prioritized during earlier stages of policy and decision-making processes. A robust accounting and recognition of these co-benefits as potential socio-economic and environmental returns on investment can help inform climate policies, strategies and decisions at national, regional and global levels.
Here we assessed the co-benefits of establishing carbon projects that focus on avoided deforestation across Southeast Asia. First, we mapped the locations of standing forests that could be protected as financially viable carbon projects based on net present values (NPVs) and considering additionality over a 30-year time frame ${ }^{2}$ (see the Methods for the details). We then modelled the extent to which carbon projects would (1) mitigate climate change from the avoided emissions from deforestation ${ }^{2}$, (2) support crop pollination services for pollinator-dependent agriculture ${ }^{8,9}$, (3) maintain water quality regulation services for downstream rivers and lakes by retaining nitrogen in watersheds ${ }^{8,9}$, and (4) safeguard Key Biodiversity Areas (KBAs) ${ }^{10}$.

We find that 114 million ha of forests in Southeast Asia could be protected as viable carbon projects $(\mathrm{NPV}>0)$ on the basis of our conservative starting carbon pricing scenario of US $\$ 5.80$ per $\mathrm{tCO}_{2} \mathrm{e}$ (refs. ${ }^{2,3,11}$ ). Protecting forests through carbon projects would thereby avoid $835 \pm 348 \mathrm{MtCO}_{2} \mathrm{e}$ of emissions from deforestation across the region per year (Fig. 1a and Supplementary Table 2). Forests in the Indonesian provinces of Riau and West Kalimantan have the greatest climate mitigation potential at up to $49 \mathrm{tCO}_{2} \mathrm{eha}^{-1} \mathrm{yr}^{-1}$.

Forest carbon projects in proximity to agricultural lands also provide important foraging and nesting habitats for wild pollinators ${ }^{4,8,9}$. These pollinators not only ensure the ecosystem health of adjoining forest patches but also support pollinator-dependent agricultural production and nutritional services within the immediate vicinity. We find that this benefit can serve the dietary needs of an equivalent of $323,739 \pm 18,725$ people across the region every year, on the basis of pollinated micronutrient production and dietary intake requirements (Fig. $1 \mathrm{~b}$ and Supplementary Table 3). This service is particularly important in the Malaysian state of Sabah, where pollination service supported by each hectare of protected forest provides enough micronutrient production to fully meet the needs of up to 42 people, with more people potentially benefiting from having their nutritional needs even partially supported by pollination.

Forests are also known to absorb nutrients such as nitrogen from the environment for biomass growth and metabolism. This uptake would in turn reduce the amount of nutrients that flow into freshwater habitats within the area's watersheds and thereby improve the quality of water flowing downstream, reducing the need for added treatment of potable water ${ }^{8,9}$. On the basis of an InVEST Nutrient Delivery Ratio model ${ }^{8,9}$, we find that $2.86 \pm 0.03 \mathrm{Mt}$ of nitrogen

'School of Biological Sciences, University of Adelaide, Adelaide, South Australia, Australia. ${ }^{2}$ Centre for Nature-Based Climate Solutions, National University of Singapore, Singapore, Singapore. ${ }^{3}$ Department of Biological Sciences, National University of Singapore, Singapore, Singapore. ${ }^{4}$ School of Public and International Affairs, Princeton University, Princeton, NJ, USA. '5epartment of Natural Resources and the Environment, Cornell University, Ithaca, NY, USA. ${ }^{6}$ Betty \& Gordon Moore Center for Science, Conservation International, Arlington, VA, USA. ${ }^{7}$ Natural Capital Project, Stanford University, Stanford,

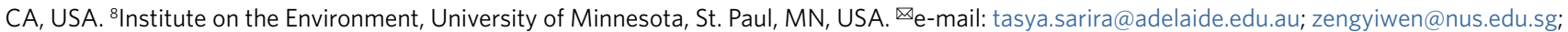
lianpinkoh@nus.edu.sg 

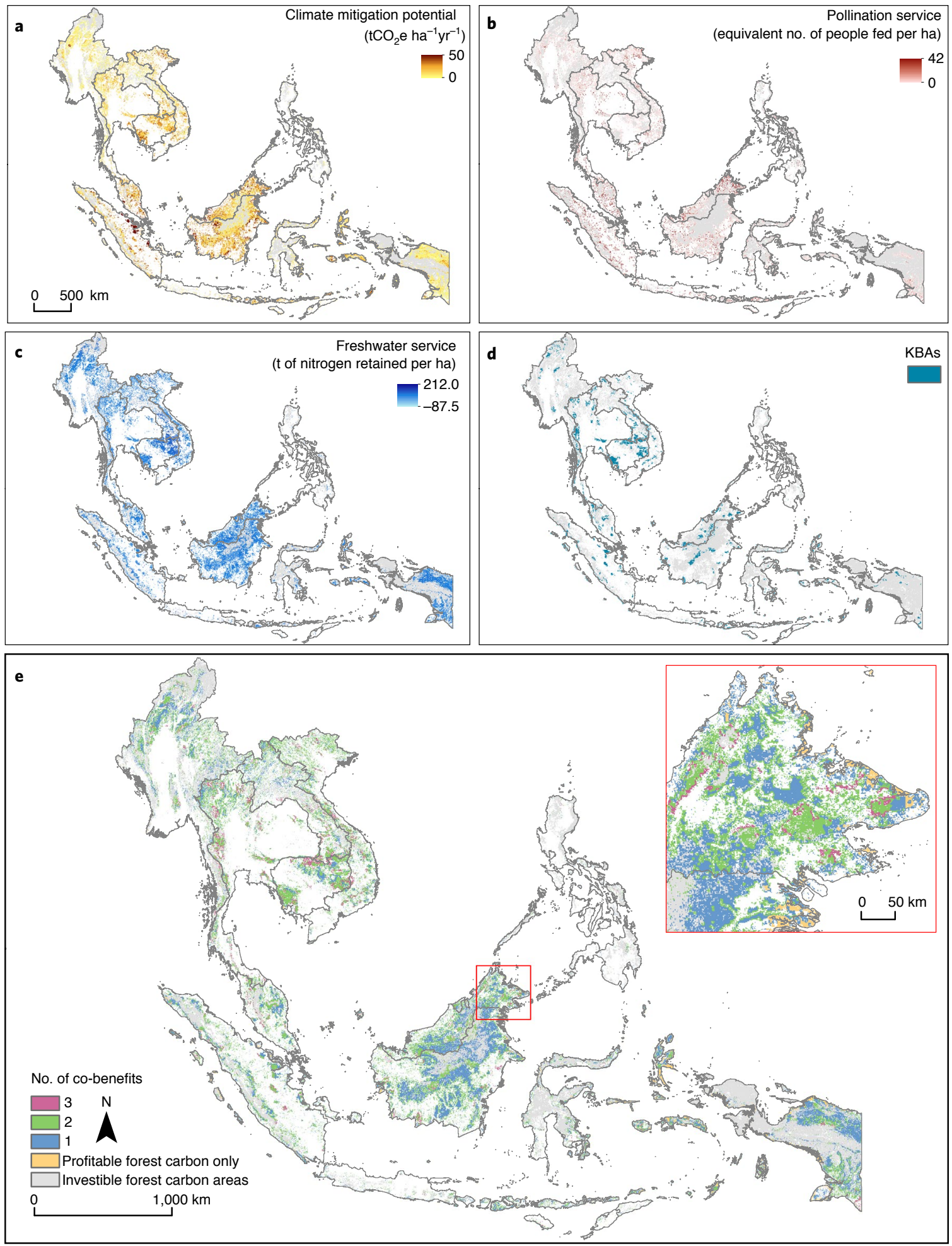

Fig. 1 | Co-benefits attained within profitable forest carbon areas at a carbon price of US $\$ 5.80$ per $\mathbf{t} \mathrm{CO}_{2} \mathrm{e}$. $\mathbf{a}$, Climate mitigation potential. $\mathbf{b}$, Pollination service. c, Freshwater service. d, KBAs. e, Spatial overlay of any level of co-benefits attained within profitable forest carbon areas. Yellow represents areas that are profitable for carbon, areas in blue provide one co-benefit in addition to carbon, areas in green provide two other co-benefits and areas in pink provide three co-benefits in addition to carbon.

pollutants (representing an estimated $78 \%$ of potential nitrogen pollutants across Southeast Asia) per year would be avoided from the establishment of carbon projects (Fig. 1c and Supplementary Table 3). This is particularly important for people who rely on the
Mekong River, where nutrient loads from surrounding agriculture may impact livelihoods and access to clean drinking water.

KBAs are sites that contribute greatly to the global persistence of biodiversity ${ }^{10}$. Protecting forests through carbon projects would 

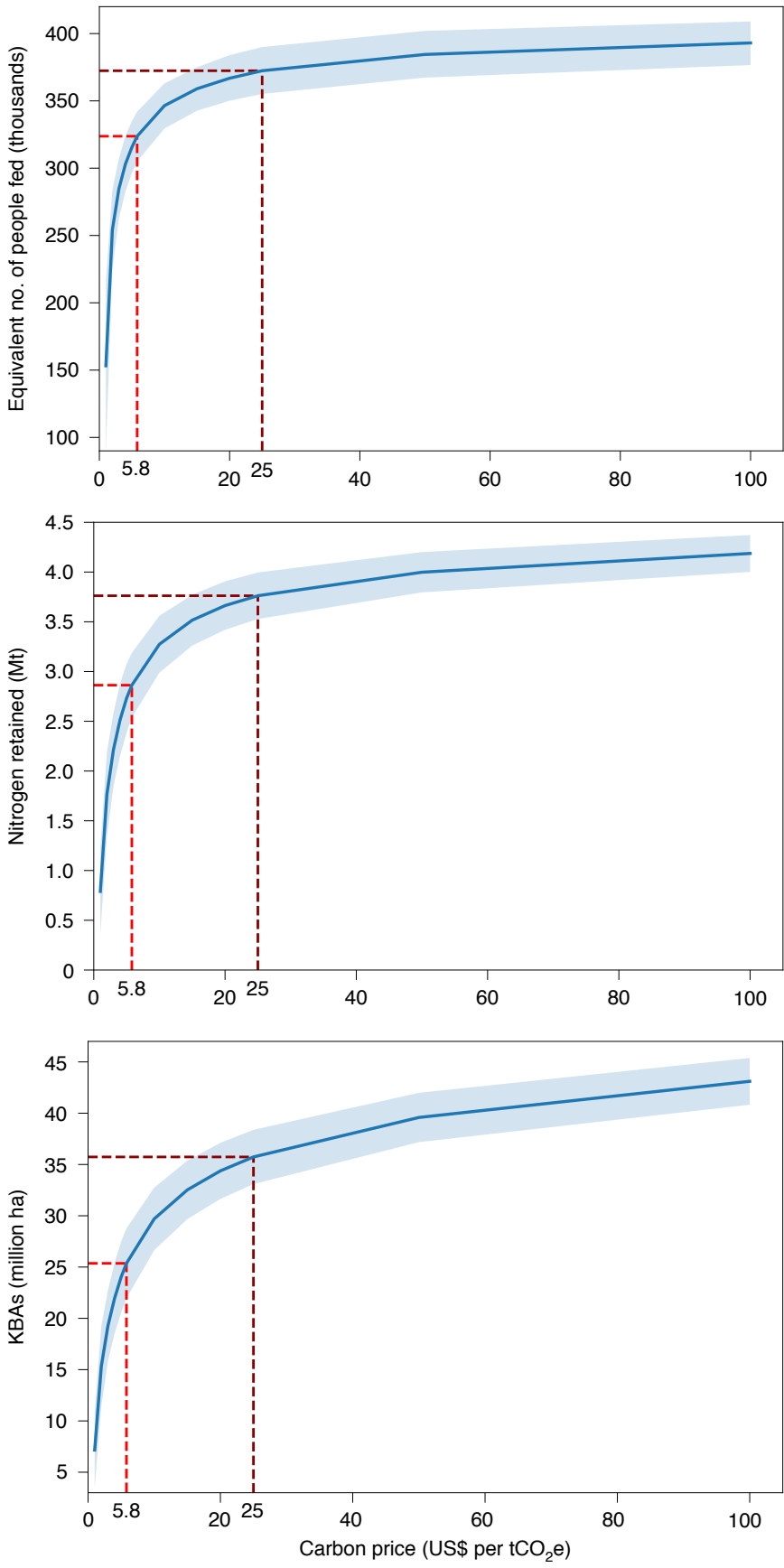

Fig. 2 | Co-benefit estimates for pollination, water quality regulation and KBAs at increasing carbon prices. The light and dark red dashed lines indicate the corresponding amount of co-benefits that could be attained at the carbon prices of US $\$ 5.8$ and US $\$ 25$ per $\mathrm{tCO}_{2} \mathrm{e}$, respectively. The light-blue shading indicates the standard deviations of the estimates.

thus conserve $25 \pm 3$ Mha of KBAs in Southeast Asia, which represents half of all terrestrial forest KBAs in the region (Fig. 1d and Supplementary Table 3).

We also identify hotspots where the establishment of carbon projects could deliver multiple co-benefits. We find that there are an estimated 6.6 Mha of forests in Southeast Asia that deliver some level of all four assessed benefits (Fig. 1e). Most of these hotspots are located in Thailand (1.7 Mha) and Indonesia (1.6 Mha). We also find that approximately $107 \mathrm{Mha}$ of forests in the region would deliver at least one co-benefit in addition to climate change mitigation.
Our findings are based on a conservative starting carbon price of US $\$ 5.80$ per $\mathrm{tCO}_{2} \mathrm{e}$ (refs. ${ }^{2,3,11}$ ). If carbon prices increased in the future, we would expect an increase in the regional extent of forests that could be protected as financially viable carbon projects. This in turn presumes an increase in the quantity of co-benefits that could be delivered to society ${ }^{7}$.

We thus performed an additional analysis to assess the effects of carbon pricing on the delivery of co-benefits from forest carbon projects in the region (Fig. 2). We find that an increase in carbon price to US $\$ 25$ per $\mathrm{tCO}_{2} \mathrm{e}$ - the average price of carbon adopted by western nations ${ }^{11}$-would result in corresponding increases in climate mitigation potential (from $835 \pm 348 \mathrm{MtCO}_{2} \mathrm{e} \mathrm{yr}^{-1}$ to $875 \pm 364 \mathrm{MtCO}_{2} \mathrm{eyr}^{-1} ; 5 \%$ increase), crop pollination (from $323,739 \pm 18,725$ to $372,390 \pm 17,225$ equivalent people fed; $15 \%$ increase), water quality regulation (from $2.86 \pm 0.03 \mathrm{Mt}$ to $3.76 \pm 0.02 \mathrm{Mt}$ of nitrogen retained; $24 \%$ increase) and biodiversity conservation ( $25 \pm 3$ Mha to $35 \pm 3$ Mha of KBAs protected; $29 \%$ increase). Further increases in carbon price would result in diminishing returns in benefits (Fig. 2 and Supplementary Tables 4 and 5).

Consequently, such increases in carbon prices could promote the financial viability of carbon projects, allowing them to compete with other potentially lucrative land-use alternatives (such as palm oil production ${ }^{12}$ ). Alternatively, mechanisms such as payments for ecosystem services and other conservation strategies could complement the establishment of carbon projects to further incentivize landholders to invest in protection and potentially increase the likelihood of the permanence of protections $\mathrm{s}^{2,12}$.

Importantly, the realization of co-benefits from forest carbon projects is essential to the alignment of climate policies such as the Paris Agreement with key global policy frameworks such as the Post-2020 Global Biodiversity Framework and the United Nations Sustainable Development Goals (SDGs). For example, forest carbon projects directly address the conservation of terrestrial ecosystems, enabling countries to better meet the targets of SDG 15.1 as well as Goal A of the Global Biodiversity Framework ${ }^{13}$. They also allow for the synergistic achievement of other goals and targets across the SDGs such as food security (SDG 2), clean water (SDG 6) and biodiversity, as well as other co-benefits not assessed in this study, such as terrestrial surface cooling (SDG 13 on climate action $)^{13}$. Quantifying forest services further exemplifies the interconnections and importance of forest ecosystems for biodiversity and people. Particularly for communities in Southeast Asia engaged in subsistence and/or smallholder agriculture, forests support their production of food and contribute to their livelihoods, as well as provide clean water for drinking and household use across the region ${ }^{4,14}$.

Naturally, forests in carbon projects can also provide many other socio-economic benefits such as recreation and cultural, gender and economic empowerment for local communities ${ }^{15}$. While these benefits are typically measured qualitatively and are important in addressing human development goals, quantifying these benefits would require a more nuanced understanding of interrelations between forest services and the realized benefits to people, as well as the socio-political ecology at the local scale ${ }^{15}$. Other types of carbon projects-namely, those focusing on reforestation and improved land management-can also contribute to mitigating climate change and provide a variety of co-benefits, though their potentials may also be limited by specific economic and social constraints ${ }^{16}$.

The investment in the protection of forests, their natural capital and their ongoing provision of services through carbon projects enables a financially viable and sustainable means of addressing other socio-economic and environmental issues beyond climate change. By assessing this potential in Southeast Asia, we demonstrate the potential of carbon finance to meet global climate and human development ambitions. 


\section{Methods}

First, we mapped areas of standing forests that could be protected as financially viable carbon projects over a 30-year time frame. Second, we modelled the extent to which carbon projects would (1) mitigate climate change from the avoided emissions from deforestation ${ }^{2},(2)$ support crop pollination services for pollinator-dependent agriculture ${ }^{8,9},(3)$ maintain water quality regulation services for downstream rivers and lakes by retaining nitrogen in watersheds ${ }^{8,9}$, and (4) safeguard KBAs ${ }^{10}$. Third, we assessed the effects of carbon pricing on the delivery of co-benefits from forest carbon projects in the region.

Standing forests in Southeast Asia were mapped on the basis of the European Space Agency's Climate Change Initiative 2015 land cover classification ${ }^{17}$ (Supplementary Table 1). We updated these forest areas to exclude recently deforested areas up to $2018^{18}$ and existing human settlements ${ }^{19}$. To harmonize our spatial data layers with Avitabile et al.'s ${ }^{20}$ carbon data (1-km resolution), we resampled (nearest neighbour) higher-resolution data where necessary.

Profitable forest carbon was determined on the basis of Koh et al. ${ }^{2}$, which estimated profitability on the basis of key carbon finance requirements such as additionality and NPV. Specifically, NPV was calculated on the basis of several simplifying assumptions, including a project establishment cost of US $\$ 25 \mathrm{ha}^{-1}$, an annual maintenance cost of US\$10 ha ${ }^{-1}$ and a carbon price of US\$5.80 per $\mathrm{tCO}_{2} \mathrm{e}$ for the first five years, followed by a $5 \%$ appreciation for the subsequent years over a 30 -year project time frame. We also applied a $10 \%$ risk-adjusted discount rate and considered profitable areas where NPV $>0$.

The regional estimates for pollination service (measured as the equivalent number of people fed), water quality regulation (in tons of nitrogen retained in the watershed) and KBAs (in hectares) within profitable forest carbon areas were then extracted from the respective spatial layers (see the Supplementary Information for the details, especially Supplementary Tables 2 and 3). We also determined locations across the region where carbon projects would deliver multiple co-benefits through a spatial overlay. Areas identified to contribute any level of co-benefit were coded 1 to 3 , indicating the number of co-benefits that could be attained in addition to climate change mitigation from avoided deforestation (Fig. 1e).

We then explored the potential for carbon prices to affect the delivery of co-benefits from forest carbon projects in the region. The carbon prices assessed included US $\$ 1$, US $\$ 2$, US\$3, US $\$ 4$, US $\$ 5$, US $\$ 10$, US $\$ 15$, US $\$ 20$, US $\$ 25$ and US $\$ 50$ per $\mathrm{tCO}_{2} \mathrm{e}$, with US $\$ 100$ per $\mathrm{tCO}_{2} \mathrm{e}$ set as the maximum on the basis of Griscom et al's ${ }^{1}$ cost-effective climate change mitigation threshold, with the same project establishment and annual maintenance cost, price appreciation, discount rates and time frame as assumed in the earlier analyses. The respective co-benefit estimates within profitable forest carbon areas at each price point were then extracted from the respective spatial layers (Supplementary Figs. 1-5).

We used uncertainties reported as standard deviations that were inherent to Avitabile et al.'s ${ }^{20}$ carbon dataset for all spatial layers. Uncertainties associated with the price of carbon, and in turn the associated co-benefit uncertainty estimates, were also based on an assumed uniform distribution of the minimum and maximum prices of carbon between 2006 and $2018^{3}$, and reported as standard deviations.

Reporting Summary. Further information on research design is available in the Nature Research Reporting Summary linked to this article.

\section{Data availability}

All maps generated are available in Zenodo at https://doi.org/10.5281/ zenodo.5572600.

\section{Code availability}

All R and Python scripts used to process the data are available from the corresponding authors upon request.

Received: 21 June 2021; Accepted: 13 January 2022; Published online: 10 February 2022

\section{References}

1. Griscom, B. W. et al. National mitigation potential from natural climate solutions in the tropics. Phil. Trans. R. Soc. B https://doi.org/10.1098/ rstb.2019.0126 (2020).

2. Koh, L. P., Zeng, Y., Sarira, T. V. \& Siman, K. Carbon prospecting in tropical forests for climate change mitigation. Nat. Commun. 12, 1271 (2021)

3. Forest Trends' Ecosystem Marketplace Financing Emission Reductions for the Future: State of Voluntary Carbon Markets 2019 (Forest Trends, 2019).

4. Sodhi, N. S. et al. Conserving Southeast Asian forest biodiversity in human-modified landscapes. Biol. Conserv. 143, 2375-2384 (2010).

5. Pearson, T. R., Brown, S., Murray, L. \& Sidman, G. Greenhouse gas emissions from tropical forest degradation: an underestimated source. Carbon Balance Manage. 12, 3 (2017).
6. Yurnaidi, Z. et al. ASEAN Climate Action: A Review of Nationally Determined Contributions Updated in 2020 (ASEAN Centre for Energy, 2021); https:// aseanenergy.org/asean-climate-action-a-review-of-nationally-determinedcontributions-ndcs-updated-in-2020/

7. Goldstein, A. Not So Niche: Co-Benefits at the Intersection of Forest Carbon and Sustainable Development (Forest Trends' Ecosystem Marketplace, 2016); https://www.forest-trends.org/publications/not-so-niche/

8. Chaplin-Kramer, R. et al. Mapping the planet's critical natural assets for people. Preprint at bioRxiv https://doi.org/10.1101/2020.11.08.361014 (2021).

9. Chaplin-Kramer, R. et al. Global modeling of nature's contributions to people. Science 366, 255-258 (2019).

10. BirdLife International The World Database of Key Biodiversity Areas (KBA Partnership, accessed 3 September 2020); www.keybiodiversityareas.org

11. Carbon Pricing Dashboard (World Bank, 2021); https:// carbonpricingdashboard.worldbank.org/

12. Butler, R. A., Koh, L. P. \& Ghazoul, J. REDD in the red: palm oil could undermine carbon payment schemes. Conserv. Lett. 2, 67-73 (2009).

13. Wood, S. L. R. et al. Distilling the role of ecosystem services in the Sustainable Development Goals. Ecosyst. Serv. 29, 70-82 (2018).

14. van Noordwijk, M. et al. Tree cover transitions and food security in Southeast Asia. Glob. Food Sec. 3, 200-208 (2014).

15. Ojea, E., Loureiro, M. L., Alló, M. \& Barrio, M. Ecosystem services and REDD: estimating the benefits of non-carbon services in worldwide forests. World Dev. 78, 246-261 (2016).

16. Zeng, Y. et al. Economic and social constraints on reforestation for climate mitigation in Southeast Asia. Nat. Clim. Change 10, 842-844 (2020).

17. Bontemps, S. et al. Consistent global land cover maps for climate modelling communities: current achievements of the ESA's land cover CCI. In Proc. ESA Living Planet Symposium ESA SP-722. 2-13 (2013).

18. Hansen, M. C. et al. High-resolution global maps of 21st-century forest cover change. Science 342, 850-853 (2013).

19. Pesaresi, M., Florczyk, A., Schiavina, M., Melchiorri, M. \& Maffenini, L. GHS-SMOD R2019A - GHS Settlement Layers, Updated and Refined REGIO Model 2014 in Application to GHS-BUILT R2018A and GHS-POP R2019A, Multitemporal (1975-1990-2000-2015) (European Commission, Joint Research Centre (JRC), 2019); http://doi.org/10.2905/42E8BE89-54FF464E-BE7B-BF9E64DA5218 (2019).

20. Avitabile, V. et al. An integrated pan-tropical biomass map using multiple reference datasets. Glob. Change Biol. 22, 1406-1420 (2016).

\section{Acknowledgements}

We thank Z. Burivalova for her contributions to improving this paper. R.N. thanks Gordon and Betty Moore for their generous gift in supporting this study. L.P.K. is supported by the National Research Foundation (NRF) Singapore under its NRF Returning Singaporean Scientists Scheme (grant no. NRF-RSS2019-007).

\section{Author contributions}

T.V.S., Y.Z., R.N. and L.P.K. conceived the study. T.V.S. carried out the analyses. Y.Z., R.N and R.C.-K. contributed to the data. T.V.S., Y.Z., R.N., R.C.-K. and L.P.K. contributed discussions and modelling insights. T.V.S., Y.Z., R.N., R.C.-K. and L.P.K. wrote the article

\section{Competing interests}

The authors declare no competing interests.

\section{Additional information}

Supplementary information The online version contains supplementary material available at https://doi.org/10.1038/s41893-022-00849-0.

Correspondence and requests for materials should be addressed to Tasya Vadya Sarira, Yiwen Zeng or Lian Pin Koh.

Peer review information Nature Sustainability thanks Christa Anderson, David Ellison and Kei Uchida for their contribution to the peer review of this work.

Reprints and permissions information is available at www.nature.com/reprints. Publisher's note Springer Nature remains neutral with regard to jurisdictional claims in published maps and institutional affiliations.

Open Access This article is licensed under a Creative Commons

Attribution 4.0 International License, which permits use, sharing, adaptation, distribution and reproduction in any medium or format, as long as you give appropriate credit to the original author(s) and the source, provide a link to the Creative Commons license, and indicate if changes were made. The images or other third party material in this article are included in the article's Creative Commons license, unless indicated otherwise in a credit line to the material. If material is not included in the article's Creative Commons license and your intended use is not permitted by statutory regulation or exceeds the permitted use, you will need to obtain permission directly from the copyright holder. To view a copy of this license, visit http://creativecommons. org/licenses/by/4.0/.

(c) The Author(s) 2022 


\section{Reporting Summary}

Nature Portfolio wishes to improve the reproducibility of the work that we publish. This form provides structure for consistency and transparency in reporting. For further information on Nature Portfolio policies, see our Editorial Policies and the Editorial Policy Checklist.

\section{Statistics}

For all statistical analyses, confirm that the following items are present in the figure legend, table legend, main text, or Methods section.

n/a Confirmed

Х $\square$ The exact sample size $(n)$ for each experimental group/condition, given as a discrete number and unit of measurement

$\bigotimes$ A statement on whether measurements were taken from distinct samples or whether the same sample was measured repeatedly

$\square$ The statistical test(s) used AND whether they are one- or two-sided

Only common tests should be described solely by name; describe more complex techniques in the Methods section.

$\bigotimes$ A description of all covariates tested

$\square$ \A description of any assumptions or corrections, such as tests of normality and adjustment for multiple comparisons

$\square$ A full description of the statistical parameters including central tendency (e.g. means) or other basic estimates (e.g. regression coefficient)

AND variation (e.g. standard deviation) or associated estimates of uncertainty (e.g. confidence intervals)

$\triangle$ For null hypothesis testing, the test statistic (e.g. $F, t, r$ ) with confidence intervals, effect sizes, degrees of freedom and $P$ value noted

$\triangle$ Give P values as exact values whenever suitable.

Х $\square$ For Bayesian analysis, information on the choice of priors and Markov chain Monte Carlo settings

$\triangle \square$ For hierarchical and complex designs, identification of the appropriate level for tests and full reporting of outcomes

Х $\square$ Estimates of effect sizes (e.g. Cohen's $d$, Pearson's $r$ ), indicating how they were calculated

Our web collection on statistics for biologists contains articles on many of the points above.

\section{Software and code}

Policy information about availability of computer code

Data collection Primary data was not collected in this study. Instead, a wide range of data sources were used for our analysis, most of which are open access e.g. Key Biodiversity Areas. The list of data sources are listed in Supplementary Table S1, following the methods the described in Methods and accompanying Supplementary Material.

Data analysis Climate mitigation potential and return-on-investment were processed and calculated using R version 3.6.0, using the 'raster' package. The analyses of ecosystem service models and subsequent integration of rasters were performed in Python 2.7.15. Map visualizations were formed in ArcGIS 10.6.1.

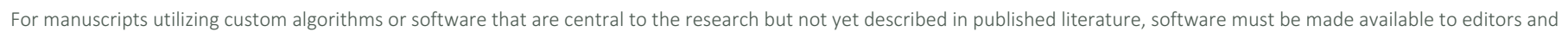

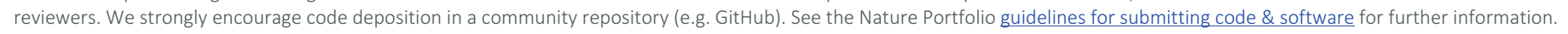

\section{Data}

Policy information about availability of data

All manuscripts must include a data availability statement. This statement should provide the following information, where applicable:

- Accession codes, unique identifiers, or web links for publicly available datasets

- A description of any restrictions on data availability

- For clinical datasets or third party data, please ensure that the statement adheres to our policy 


\section{Field-specific reporting}

Please select the one below that is the best fit for your research. If you are not sure, read the appropriate sections before making your selection.

Life sciences

Behavioural \& social sciences

Ecological, evolutionary \& environmental sciences

For a reference copy of the document with all sections, see nature.com/documents/nr-reporting-summary-flat.pdf

\section{Ecological, evolutionary \& environmental sciences study design}

All studies must disclose on these points even when the disclosure is negative.

Study description

While there is growing demand for high-quality, nature-based carbon credits by public and private sectors to meet their climate goals through certified carbon projects, the co-benefits from carbon projects are typically documented at the project level, rather than being systematically considered during earlier stages of policy and decision-making processes at national and regional levels. We assessed the co-benefits of forest conservation through high-quality, nature-based carbon projects by first mapping forests across Southeast Asia that could be protected for financially viable carbon projects. Then, we modeled the extent to which forest protection would (i) contribute to climate change mitigation, (ii) support crop pollination services for pollinator-dependent agriculture, (iii) regulate water quality and (iv) protect biodiversity.

Research sample N/A

Sampling strategy N/A

Data collection Data was collated from multiple publications and datasets available online. Y.Z., T.V.S. and L.P.K. contributed to forest carbon datasets, while R.N. and R.C.K contributed key ecosystem service datasets.

Timing and spatial scale Analyses was done for Southeast Asia, based on data assessed from 2015-present.

Data exclusions No data was excluded.

Reproducibility Uncertainty analyses was performed to ensure reproducibility.

Randomization No randomization was needed for this study.

Blinding No blinding was needed for this study.

Did the study involve field work? $\square$ Yes $\quad$ No

\section{Reporting for specific materials, systems and methods}

We require information from authors about some types of materials, experimental systems and methods used in many studies. Here, indicate whether each material, system or method listed is relevant to your study. If you are not sure if a list item applies to your research, read the appropriate section before selecting a response.

Materials \& experimental systems

$\mathrm{n} / \mathrm{a}$ Involved in the study

\ $\square$ Antibodies

\ $\square$ Eukaryotic cell lines

$\bigotimes \square$ Palaeontology and archaeology

\ $\square$ Animals and other organisms

\ $\square$ Human research participants

Х $\square$ Clinical data

\ $\square$ Dual use research of concern
Methods

$\mathrm{n} / \mathrm{a}$ Involved in the study

\ $\square$ ChIP-seq

Х $\square$ Flow cytometry

\| $\square$ MRI-based neuroimaging 